\title{
Editorial: Thinking Skills
}

The Government is, it seems, keen to introduce 'thinking skills' into the curriculum. Of course, no one could be against people, young or old, thinking. Nor would it be appropriate in a philosophical journal to cast doubt on an initiative that might expand the market for philosophers. Nevertheless, one may he forgiven for wondering just what is being envisaged by the notion of thinking skills.

Are these, in the modern jargon, 'transferable'? Can someone who can think excellently about physics thereby think well about practical matters? Is there such a thing as musical thought, or painterly thinking? Are those who can compose or paint well necessarily any good at thinking when it comes to horse racing or tax returns?

Perhaps what is meant is something like the ability to do some formal and informal logic. No doubt it would be a good thing if people avoided the more glaring fallacies in their thinking, but that does not get us very far (two lessons, maybe). And there is no guarantee that those expert at logic, formal and informal, are going to be much good when it comes to thinking about other people, or even about politics. (All the usual suspects, starting with Frege and Russell.)

In any case, even in philosophy, the relationship between perennial fascination and thought in any straightforward, argumentative sense is by no means clear. Every first year undergraduate is given a quiver-full of arguments to show that Descartes and Plato can be punctured at crucial points, and, in Jonathan Bennett's words, every great philosopher is fought 'tooth and nail' at every step by those who follow. Mostly this has a disconcertingly small effect on the reputation of those who have a vision and a breadth to compel. If philosophy is a guide, what counts in the end are not thinking skills, but generosity of vision and human resonance: qualities which cannot be characterized as skills at all. 